Article

\title{
Carbon Nanotubes-Based Potentiometric Bio-Sensors for Determination of Urea
}

\author{
Ewa Jaworska, Krzysztof Maksymiuk and Agata Michalska * \\ Department of Chemistry, Warsaw University, Pasteura 1, Warsaw 02-093, Poland; \\ E-Mails: ewa7jaworska@wp.pl (E.J.); kmaks@chem.uw.edu.pl (K.M.) \\ * Author to whom correspondence should be addressed; E-Mail: agatam@ chem.uw.edu.pl; \\ Tel.: +48-22-8220211.
}

Academic Editor: Johan Bobacka

Received: 28 April 2015 / Accepted: 15 July 2015 / Published: 24 July 2015

\begin{abstract}
The possibility of using disposable plastic-carbon potentiometric sensors as enzyme biosensors was examined. Urease enzyme was immobilized on poly(vinyl chloride) based $\mathrm{H}^{+}$- or $\mathrm{NH}_{4}{ }^{+}$-selective membranes using cellulose acetate. This approach has resulted in a potentiometric response on changing the $\mathrm{pH}$ of the solution $\mathrm{Or}^{-} \mathrm{NH}_{4}{ }^{+}$ion content due to an enzymatic reaction that occurs between urease and urea. Both types of potentiometric biosensors for urea were characterized by good analytical parameters as high sensitivity and fast response time.
\end{abstract}

Keywords: urea; potentiometry; disposable sensor; carbon nanotube; ion-selective electrode

\section{Introduction}

Determination of urea is important in terms of clinical research, as well as other environmental and industrial applications. One of the attractive, and often considered, methods for the determination of urea is to use potentiometric biosensors based on ion-selective electrodes [1-3]. This approach offers potentially fast and relatively simple, in terms of the apparatus applied, quantification of urea. The other benefit of potentiometric approach is that ion-selective electrodes are well-established tools of clinical and biological analysis. 
In the presence of the enzyme, hydrolysis of urea is observed resulting, ultimately, in $\mathrm{pH}$ change.

$$
\mathrm{NH}_{2} \mathrm{CONH}_{2}+2 \mathrm{H}_{2} \mathrm{O}+\mathrm{H}^{+} \rightarrow \mathrm{HCO}_{3}{ }^{-}+2 \mathrm{NH}_{4}{ }^{+}
$$

In principle, two sensing modes can be used to follow the enzymatic-driven decomposition of urea, either following an $\mathrm{H}^{+}$ion concentration decrease or the increase of the $\mathrm{NH}_{4}{ }^{+}$ion content.

Both ammonium ion- and hydrogen ion-plastic, solvent polymeric (i.e., plasticized poly(vinyl chloride)-based), ion-selective membrane electrodes are well known sensors. (e.g., [4-6]). Their high sensitivity, low detection limit, and fast response time provide an opportunity to use them for preparation of urea biosensors. Moreover, both $\mathrm{H}^{+}$and $\mathrm{NH}_{4}{ }^{+}$ion-selective electrodes can and have been prepared in the internal-solution free arrangement, which is generally highly promising for miniaturization and disposable sensors. Among other potential materials tested, in recent years for all-solid state transducers for potentiometric electrodes, carbon nanotubes (CNTs) have attracted significant research attention [7-11]. Carbon nanotubes can be applied on the glassy carbon surface and then covered by an ion-selective membrane [7-9]. Alternatively, carbon nanotubes can be also useful to prepare (nominally) disposable sensors, where CNTs are used both as a transducer and as an electrical lead [12-14]. The latter concept is especially attractive to develop further in order to obtain disposable potentiometric biosensors. The general idea of such devices requires that the bio-molecule should be immobilized at the outer interface of the ion-selective membrane. In this way the biological reaction (e.g., enzymatic hydrolysis of urea) would generate a product close to the outer interface of the ion-selective membrane, allowing fast detection and assuring low detection limits.

Thus, an important aspect of potentiometric enzymatic biosensor construction is the choice of the appropriate method of the enzyme immobilization on the ion-selective membrane surface. The major issues here are preservation of the activity of the enzyme as well as the preferred analytical parameters. The literature describes the physical (adhesion, inclusion) and chemical (cross-linking [15], covalent linking [16]) methods of enzymes immobilization. It is possible to use cellulose or poly(vinyl chloride) as a medium to urease immobilization on the surface of glass pH-electrodes [17]. The covalent linking of the enzyme to a poly(vinyl alcohol) matrix [18] or covalent attachment of enzyme molecules directly on the membrane using carboxylated poly(vinyl chloride) [19] have been reported as effective methods of enzyme immobilization. This material has been also used to obtain urea $\mathrm{pH}$-biooptrode [20].

This paper presents a possibility of using multi-walled carbon nanotubes to prepare disposable carbon-plastic potentiometric sensors, using the approach developed in our group earlier [13]. In this work, the key interest was to prepare a simple methodology allowing for potentiometric readout. The sensors prepared were either ammonium- or hydrogen ion-selective. The ion-selective membranes were further modified with urease enzyme-immobilized with acetate cellulose on the top of ion-selective membranes.

\section{Experimental}

\subsection{Reagents and Equipment}

Urease (from Canavalia ensiformis (Jack bean), 50,000-100,000 U/g), tetrahydrofuran (THF), cellulose acetate, chloroform, poly(vinyl chloride) (PVC), bis(2-ethylhexyl) sebacate (DOS), nonactin ionophore, tridodecylamine (TDDA), sodium or potassium tetrakis[3,5-bis(trifluoromethyl)phenyl]borate 
(NaTFPB or KTFPB), multi-walled carbon nanotubes (MWCNTs), urea, and tris(hydroxymethyl)aminomethane (Tris) were from Fluka AG (Buchs, Switzerland) or from Aldrich (Germany). All other reagents used were analytical grade salts from POCh (Poland) or Sigma. Doubly-distilled and freshly deionized water (resistance $18.2 \mathrm{M} \Omega \mathrm{cm}$, Milli-Q plus, Millipore, Austria) was used throughout this work. In the potentiometric experiments and electrochemical measurements the experimental setup and electrodes described earlier [21] were used. A dispersion of carbon nanotubes in THF (ink) was obtained using a UP200S Hielscher Ultrasonic GmbH (Tetlow, Germany) for $2 \mathrm{~h}$ ( $200 \mathrm{~W}$, frequency of $24 \mathrm{kHz}, 70 \%$ of amplitude and a cycle $0.5 \mathrm{~s}$ ). The recorded potential values were corrected for the liquid junction potential calculated according to the Henderson approximation.

\subsection{Multi-Walled Carbon Nanotubes}

Multi-walled carbon nanotubes (MWCNTs) were purified by boiling in concentrated (35\% w/w) hydrochloric acid for $1 \mathrm{~h}$. Following this treatment, MWCNTs were filtered and washed with deionized water until neutrality of the outflow was achieved.

\subsection{Preparation of Carbon-Plastic Electrodes}

Dispersion of MWCNTs was prepared by weighing carbon nanotubes and PVC, the proportion by weight being $1 \mathrm{mg}$ of carbon nanotubes per $0.2 \mathrm{mg}$ of PVC. Following addition of THF $(135 \mu \mathrm{L}$ per $1 \mathrm{mg}$ ) the dispersion was prepared using a tip sonicator.

Carbon-plastic electrodes were prepared on acetate transparency sheets as described earlier [13,22,23] using $90 \mu \mathrm{L}$ of MWCNT/PVC suspension. After drying, a strip of PTFE adhesive was applied to isolate the transducer and the electrical lead parts of the layer. On these prepared layers of carbon nanotubes, conventional cocktails of ion-selective membranes were applied.

\subsection{Ion-Selective Membranes}

Hydrogen-selective electrode, $\mathrm{H}^{+}$-ISE, membranes contained (by weight) $0.6 \%$ KTFPB, $1 \%$ TDDA, 63.7\% DOS and 34.7\% PVC. A total of $100 \mathrm{mg}$ were dissolved in $1 \mathrm{~mL}$ of THF.

Ammonium-selective electrode, $\mathrm{NH}_{4}{ }^{+}$-ISE, membrane contained (by weight) $0.8 \% \mathrm{NaTFPB}, 1.8 \%$ nonactin, $60.8 \%$ DOS, 36.6 PVC. A total of $100 \mathrm{mg}$ were dissolved in $1 \mathrm{~mL}$ of THF. $30 \mu \mathrm{L}$ of the membrane cocktail was applied per electrode.

\subsection{Preparation of Biosensors}

After the ion-selective membrane was formed, urease, dissolved in water $(77.75 \mathrm{mg} / \mathrm{mL})$, was applied on the surface of ion-selective membrane. $40 \mu \mathrm{L}$ was applied per electrode and left overnight. The amount of urease used was balanced between the required sensitivity of response, i.e., the amount of analyte formed in the enzymatic reaction in unit time and aimed at a low cost of a nominally disposable sensor.

After evaporation of water, cellulose acetate solution $(2.5 \mathrm{mg} / \mathrm{mL})$ was dropped on the enzyme layer. $10 \mu \mathrm{L}$ was applied and left for $3 \mathrm{~h}$ for chloroform evaporation at room temperature. The outline of the sensor is shown in Scheme 1. 


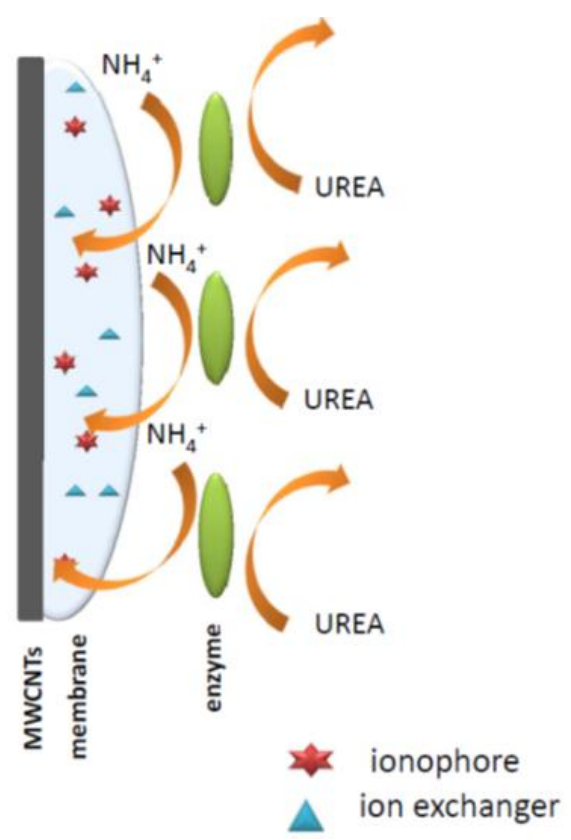

Scheme 1. The schematic outline of sensor used in this work.

\section{Results and Discussion}

Figure 1 presents typical potentiometric responses obtained for miniature, disposable, plastic-carbon ammonium ion-selective electrodes (without urease). As it can be seen in Figure 1, the sensors were characterized with linear responses within the broad activity range from $10^{-1}$ to $10^{-6} \mathrm{M}$, with a detection limit close to $10^{-6.6} \mathrm{M}$ and close to the Nernstian slope, equal to $59.4 \pm 0.9 \mathrm{mV} / \mathrm{dec}$ $\left(\mathrm{R}^{2}=0.999\right)$. The logarithms of selectivity coefficients for the ammonium ion-selective electrode (calculated using the Nernstian slope for activities from $10^{-1} \mathrm{M}$ to $10^{-4} \mathrm{M}$, separate solution method) were equal to $-4.44 \pm 0.5,-4.73 \pm 0.4,-0.95 \pm 0.04,-2.99 \pm 0.01$ for $\mathrm{Mg}^{2+}, \mathrm{Ca}^{2+}, \mathrm{K}^{+}, \mathrm{Na}^{+}$cations, respectively. The above given analytical parameters clearly confirm that these miniature, nominally-disposable sensors were successfully obtained.

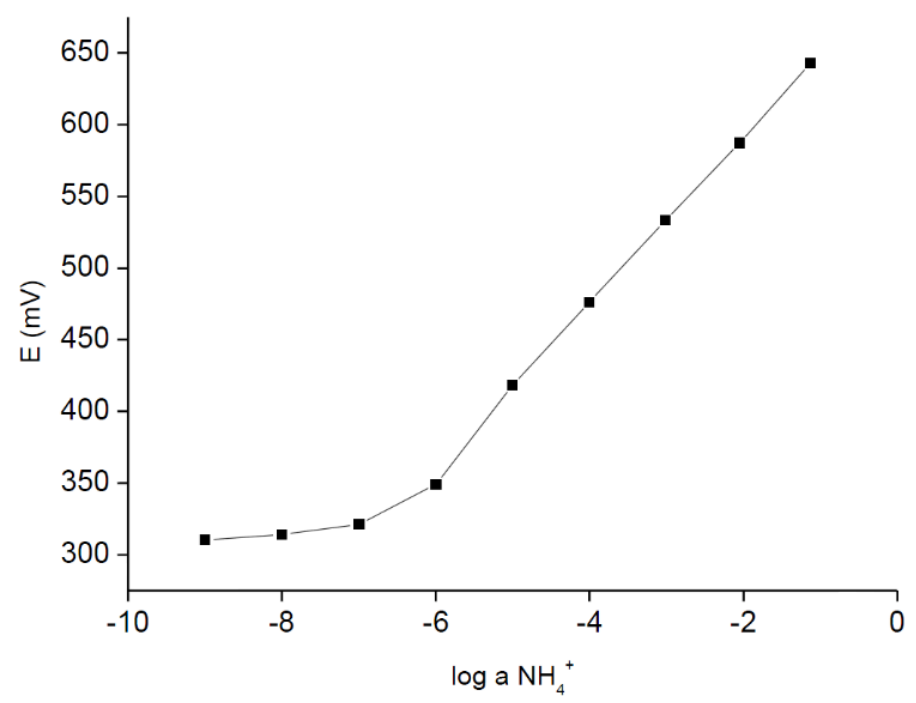

Figure 1. Potentiometric response of ammonium ion-selective carbon-plastic sensor recorded in $\mathrm{NH}_{4} \mathrm{Cl}$ solutions. 
The $\mathrm{H}^{+}$-selective electrode tested in parallel (without urease) were also characterized with potentiometric responses typical for its full-size, solid-contact or internal solution counterparts (Figure 2). As it can be seen in Figure 2, the sensor was characterized with linear responses within the broad activity range from $10^{-2} \mathrm{M}$ to $10^{-6} \mathrm{M}$, with a detection limit close to $10^{-6} \mathrm{M}$; the slope of dependence was close to Nernstian, within the range of experimental error, and was equal to $57.7 \pm 0.7 \mathrm{mV} / \mathrm{dec}\left(\mathrm{R}^{2}=0.999\right)$. The logarithms of selectivity coefficients (determined using theoretical slope, separate solution method, within the concentration range from $10^{-1} \mathrm{M}$ to $10^{-4} \mathrm{M}$ ) were equal to $-4.93 \pm 0.5,-4.48 \pm 0.7,-3.28 \pm 0.1,-3.98 \pm 0.4$ for $\mathrm{Mg}^{2+}, \mathrm{Ca}^{2+}, \mathrm{K}^{+}$and $\mathrm{Na}^{+}$ cations, respectively.

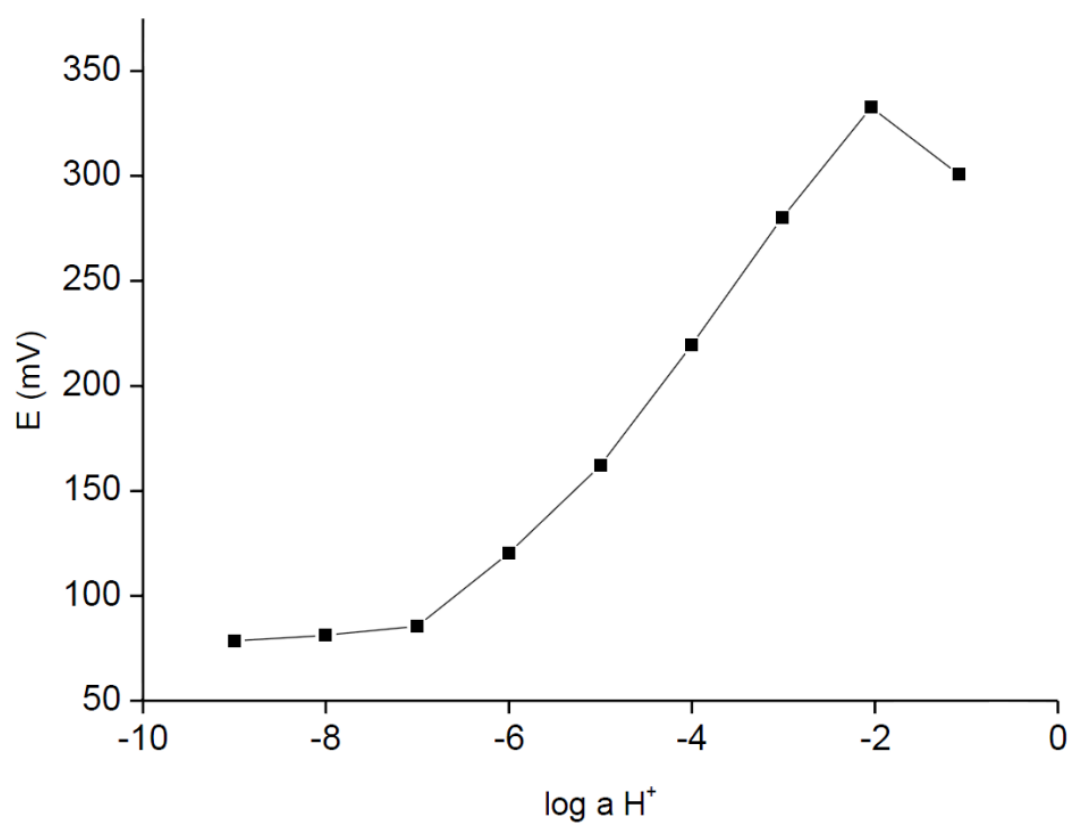

Figure 2. Potentiometric response of $\mathrm{H}^{+}$-ISE carbon-plastic electrodes recorded in $\mathrm{HCl} /$ buffer solutions.

When the PVC-based ion-selective membranes were covered with urease in the cellulose acetate layer, some alteration of the potentiometric response to the $\mathrm{H}^{+}$or $\mathrm{NH}_{4}{ }^{+}$ions was observed, for $\mathrm{H}^{+}$-ISE or $\mathrm{NH}_{4}{ }^{+}$-ISE, respectively, in the absence of urea in solution. The slope of the dependence obtained for $\mathrm{H}^{+}$-ISE electrodes with the PVC surface modified with urease in cellulose acetate was close to $32.0 \mathrm{mV} / \mathrm{dec}$, in the range from $10^{-2} \mathrm{M}$ to $10^{-4} \mathrm{M}\left(\mathrm{R}^{2}=0.998\right)$. Further, a decrease of solution $\mathrm{H}^{+}$ion activity resulted in a decrease of potential; however, the slope of dependence further decreased. Similarly, for the $\mathrm{NH}_{4}{ }^{+}$-ISE surface modified with urease in cellulose acetate, the slope of potentiometric dependence was lower than Nernstian and was close to $38.0 \mathrm{mV} / \mathrm{dec}$, in the range from $10^{-1} \mathrm{M}$ to $10^{-5} \mathrm{M}\left(\mathrm{R}^{2}=0.996\right)$.

The lower slope of the dependence recorded in the presence of cellulose acetate and the urease layer on the surface of the ion-selective membrane can be related to limitation in transport/ion-exchange at the ion-selective membrane/solution interface and to the $\mathrm{pH}$ buffering effect of this layer. The effect of the presence of the outer layer on the ion-selective membrane was more pronounced for $\mathrm{H}^{+}$-ISE, which is probably related to the possibility of protonation/deprotonation of enzyme proteins in the cellulose acetate layer. As a result, the changes of $\mathrm{H}^{+}$ions directly at the membrane surface, i.e., where the 
signal is formed, are different from those occurring in the solution bulk. The effect of the surface enzyme-containing layer presence on the performance of $\mathrm{NH}_{4}{ }^{+}$-ISE was less pronounced, as in this case the effect is primarily attributed to analyte transport limitation.

The above-described effects should not affect the performance of the biosensors, in which the changes of $\mathrm{pH}$ due to enzymatic reaction are occurring in the ion-selective membrane modifying layer - that is at the ion-selective membrane interface.

For application of ion-selective electrodes with enzyme immobilized on the surface of ion-selective membranes for urea detection, the choice of background buffer and solution $\mathrm{pH}$ is vitally important. The choice of optimal pH is dependent on the enzyme-optimal activity, as well as on the analyte to be detected potentiometrically.

For the $\mathrm{NH}_{4}{ }^{+}$-selective membrane the potentiometric detection requires rather low $\mathrm{pH}$ to favor the presence of the ammonium ions close to the membrane surface and prevent its spontaneous transformation to yield ammonia. Conversely, the optimal $\mathrm{pH}$ of the urease activity is close to 7.4 [24]. Thus, clearly the measurement should be performed after adjustment of the sample $\mathrm{pH}$, post enzymatic reaction. It should be stressed that the decrease of $\mathrm{pH}$ is expected to affect, mainly, the detection limit, as the amount of $\mathrm{NH}_{4}{ }^{+}$ions present in the solution of constant total ammonium ion concentration is $\mathrm{pH}$-dependent. Figure 3 presents potentiometric responses of urea biosensors (urease- $\mathrm{NH}_{4}{ }^{+}$-ISE) for different concentrations of urea in the solution, recorded for different working $\mathrm{pH}$ values. As it can be seen from Figure 3, the detection limit of urease- $\mathrm{NH}_{4}{ }^{+}$-ISE significantly depends on the working solution $\mathrm{pH}$. The highest detection limit was obtained for a working solution $\mathrm{pH}$ equal to 7.19 and was equal to $10^{-3} \mathrm{M}$ of urea in solution. The slope of potentiometric dependence was equal to $55.9 \pm 1.7 \mathrm{mV} / \mathrm{dec}\left(\mathrm{R}^{2}=0.999\right)$.

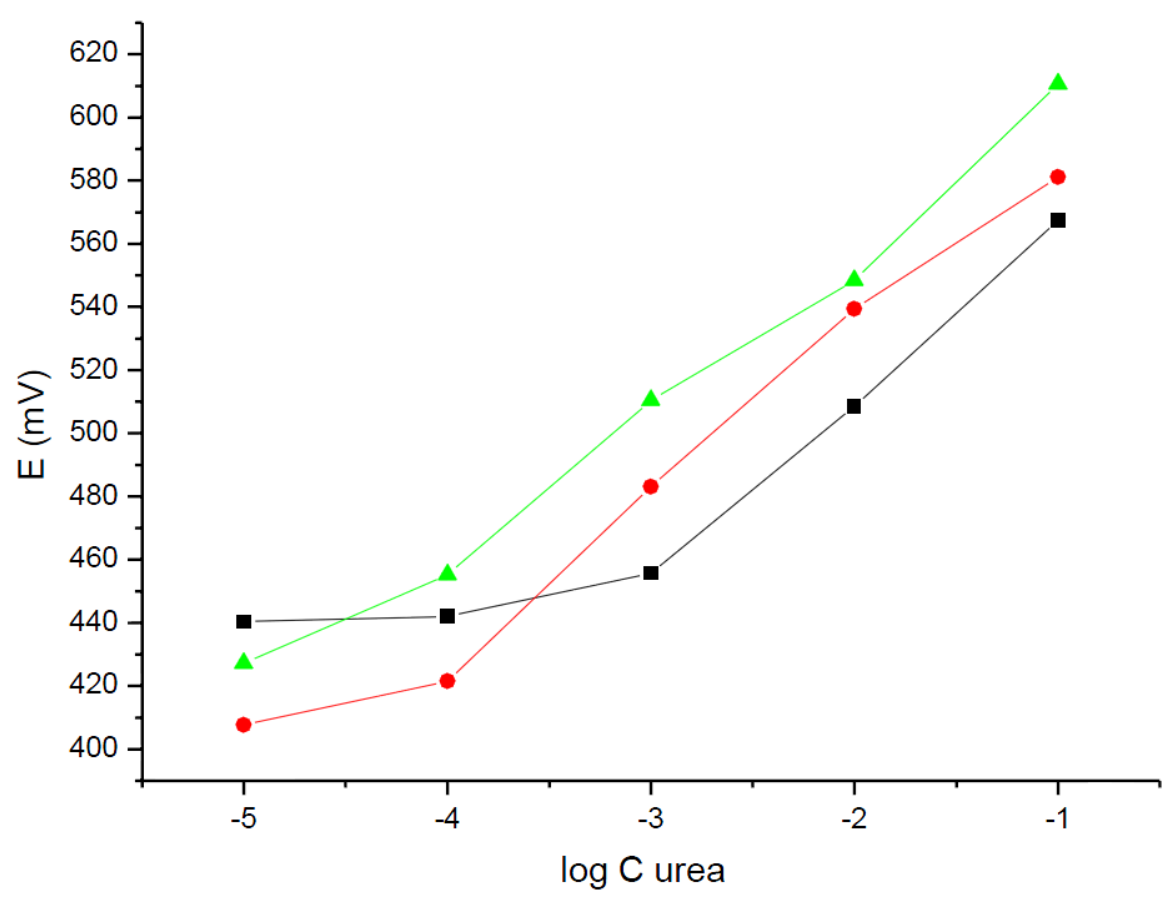

Figure 3. Potentiometric response of urea biosensors based on the ammonium ion-selective carbon-plastic electrodes in $(\bullet) 10^{-4} \mathrm{M}$ Tris $\mathrm{pH}=7.19,(\bullet) \mathrm{H}_{2} \mathrm{O}$, and $(\Delta) 0.1 \mathrm{M}$ acetate buffer $\mathrm{pH}=5.35$ solutions. 
If the determination was performed in the absence of a buffer, just in deionized water of $\mathrm{pH}$ close to 6.5 , the linear dependence of potential on urea concentration in solution ranged from $10^{-1} \mathrm{M}$ to $10^{-4} \mathrm{M}$, with a detection limit close $10^{-4} \mathrm{M}$. The slope of the dependence was within the range of experimental error, equal to that obtained in a Tris buffer of $\mathrm{pH}=7.19$ and was equal to $53.5 \pm 3.2 \mathrm{mV} / \mathrm{dec}\left(\mathrm{R}^{2}=0.993\right)$.

For the measurements performed in an acetic buffer of $\mathrm{pH}=5.35$ (first the sensor was in contact with urea water solution for $5 \mathrm{~min}$, then the solution $\mathrm{pH}$ was adjusted by addition of an acetic buffer, for the potentiometric measurement) the detection limit of urea obtained was equal to $10^{-5} \mathrm{M}$. The linear dependence within the range from 0.1 to $10^{-5} \mathrm{M}$ was characterized with a slope of $50.0 \pm 5.3 \mathrm{mV} / \mathrm{dec}$. $\left(\mathrm{R}^{2}=0.968\right)$. Thus, the slope of the dependence was within the limit of experimental error, comparable to above given values.

The observed detection limit dependence on the $\mathrm{pH}$ of the working solution results from the simple $\mathrm{pH}$ dependence of $\mathrm{NH}_{4}{ }^{+}$ion concentration for the total ammonium ion concentration, $\mathrm{C}$, in solution:

$$
\left[\mathrm{NH}_{4}^{+}\right]=\frac{\mathrm{C}}{\left(\frac{K_{\mathrm{a}}}{\mathrm{H}^{+}}+1\right)}
$$

Taking into account that $\mathrm{K}_{\mathrm{a}}$ of $\mathrm{NH}_{4}{ }^{+}$is close to $10^{-9.2}$, it can be expected that, for a solution of $\mathrm{pH}=5.35$ (acetic buffer used), practically all $\mathrm{NH}_{4}{ }^{+}$ions generated as a result of urea enzymatic hydrolysis are present in solution as ammonium ions, i.e., $\mathrm{C}$ is close to $\left[\mathrm{NH}_{4}^{+}\right]$. Conversely, for slightly alkaline solution of $\mathrm{pH}=7.19$ (Tris buffer used), about $1 \%$ of total ammonium ion concentration is present in the solution as $\mathrm{NH}_{3}$. However, from the dependence presented in Figure 3, it is clear that the shift in the detection limit of potentiometric biosensor tested for the change of working solution $\mathrm{pH}$ from 5.35 to 7.19 is close to two orders of magnitude. This effect clearly points to a local effect of amplification (for $\mathrm{pH}=5.35$ ) or attenuation (for $\mathrm{pH}=7.19$ ) of the analytical signal obtained by simple solution equilibrium means.

Furthermore, for the urea detection based on the change of $\mathrm{pH}$ of the sample, due to alkalization of the solution in the course of enzymatic hydrolysis of urea, to maximize the sensitivity the $\mathrm{pH}$ of the working solution should be kept rather high to prevent spontaneous conversion of ammonia generated to ammonium ions.

To check the effect of $\mathrm{pH}$ on the responses of urease- $\mathrm{H}^{+}$-ISE, the dependences of potential recorded on the change of urea concentration was recorded in a solution of Tris buffer $(\mathrm{pH}=7.19)$ and in deionized water (Figure 4). Similarly, as in the case of urease- $\mathrm{NH}_{4}{ }^{+}-\mathrm{ISE}, \mathrm{pH}$ change has a profound effect on the obtained responses. The decrease of potential recorded in the $10^{-4} \mathrm{M}$ Tris buffer $(\mathrm{pH}=7.19)$ for the change in the urea concentration in solution was observed within the range form $10^{-4} \mathrm{M}$ to $0.1 \mathrm{M}$. The dependence recorded was not linear and higher sensitivity was observed for lower concentrations of urea in solution. This effect can be attributed to the low buffering capacity of the buffer used. The low capacity was chosen to minimize the buffering effect, to lower the interfering ions influence (i.e., ions present in the buffer), and to allow manifestation of the sample $\mathrm{pH}$ by a change of the electrode potential. Nevertheless, the effect of preventing spontaneous protonation of ammonia to form $\mathrm{NH}_{4}{ }^{+}$was achieved only at the low urea concentration tested. 


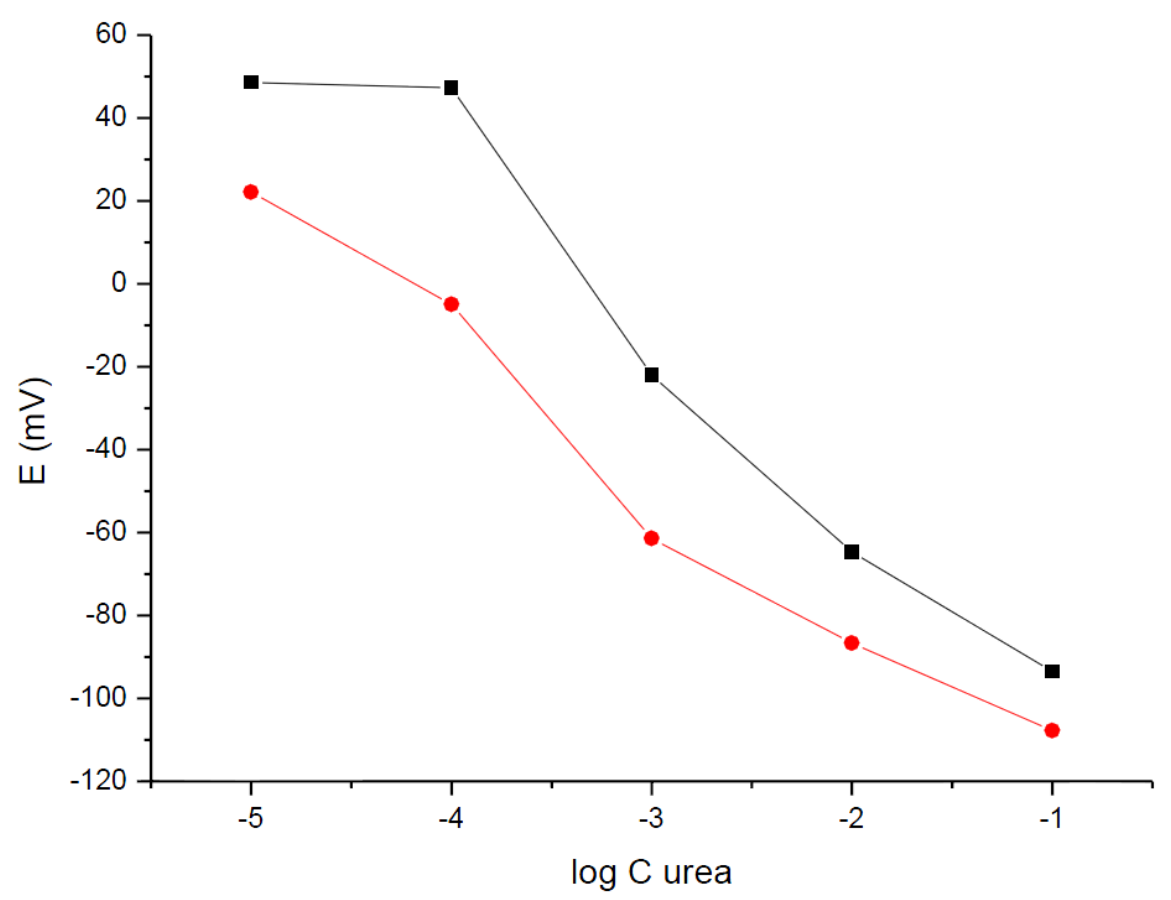

Figure 4. Potentiometric response of urea biosensors using $\mathrm{H}^{+}$-ISE carbon-plastic electrodes recorded in (-) $10^{-4} \mathrm{M}$ Tris, $\mathrm{pH}=7.19$ and $(\bullet) \mathrm{H}_{2} \mathrm{O}$.

Working in deionized water (in the absence of buffer) has the advantage of being a relatively sensitive system. Indeed, in the absence of a buffer, the significant potential change was observed when the urea concentration in the sample was changed from $10^{-5}$ to $10^{-4} \mathrm{M}$ (detection limit close to $10^{-5} \mathrm{M}$ ). For the higher urea concentrations, similarly as in the case of the Tris buffer-containing samples described above, the potential dependence was observed; however, this relation was not linear. It should be stressed that for low concentration ranges (where the dependence of potential on the logarithm of concentration of urea is close to linear) the sensitivity, defined as a change of the potential per order of magnitude urea concentration, the change was lower for measurements performed in deionized water. The reproducibility of responses obtained for different, but nominally the same, sensors was in the range of single millivolts, but it can be probably further optimized if the sensor production method is automated.

To compare the response time of $\mathrm{H}^{+}$- and $\mathrm{NH}_{4}{ }^{+}$-selective ISEs, with ion-selective membranes modified with urease in cellulose acetate layer, the potential accompanying change of the urea concentration $\left(10^{-3} \mathrm{M}\right)$ in solution was followed for both sensors, while working in DI water (Figure 5). As it can be seen from Figure 5, both sensors quite rapidly respond to the introduction of urea to the solution. The response stabilizes faster for $\mathrm{NH}_{4}{ }^{+}$-ISE; after about $100 \mathrm{~s}$ a stable potential is recorded. Conversely, for $\mathrm{H}^{+}$-ISE, after the abrupt potential change directly after introduction of urea to the sample, a small potential change is observed even for the longer times tested. This, in our opinion, can be related to participation of the biosensing layer in protolitic equilibrium. 


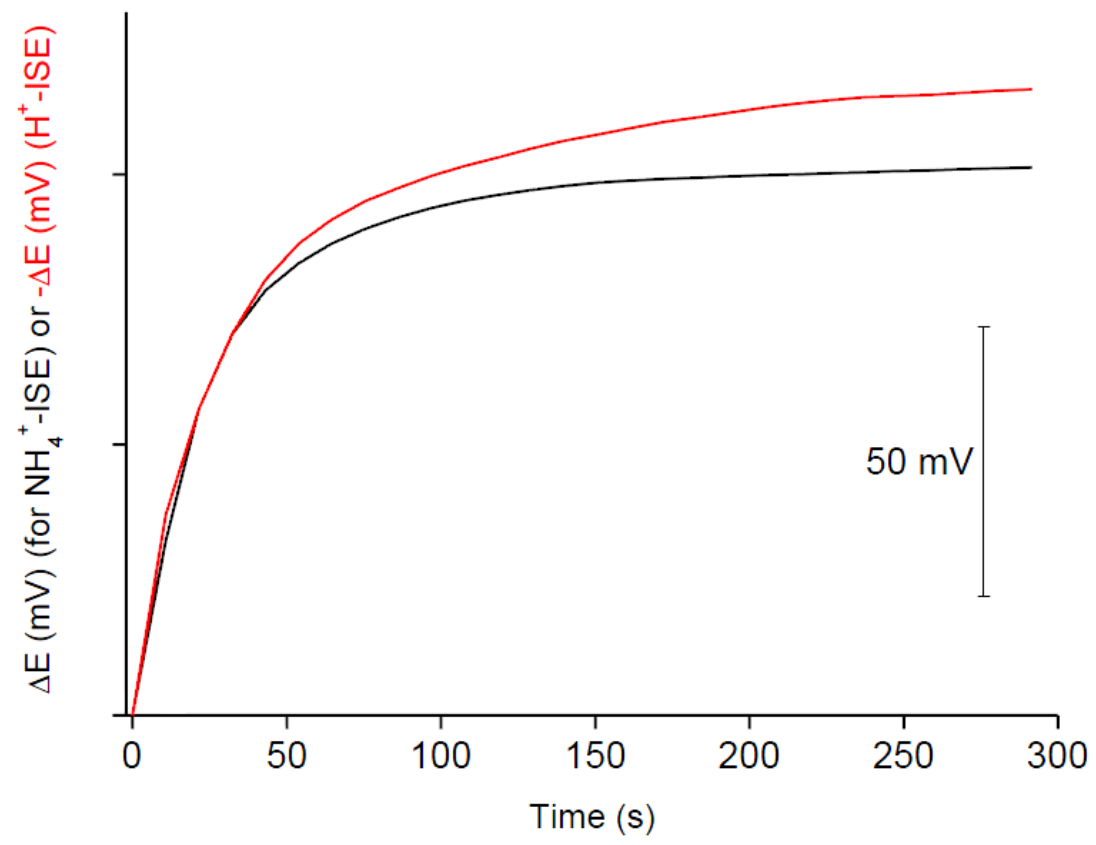

Figure 5. The change of the potential recorded for biosensors containing urease in a cellulose acetate layer for $\mathrm{H}^{+}$-ISE (red line) and for $\mathrm{NH}_{4}{ }^{+}$-ISE (black line), following introduction $10^{-3} \mathrm{M}$ urea to the unbuffered (i.e., DI water-containing) sample. The lines were shifted to give the same starting potentials; for $\mathrm{H}^{+}$-ISE, when the decrease of potential is recorded, the negative potential change was plotted.

\section{Conclusions}

From the above-presented results, it follows that simple, disposable carbon-plastic electrodes, using CNTs as a transducer for ion-selective membranes and electrical leads, are potentially useful tools as urea biosensors. Taking into account the performance of the sensors, the following recommendation can be made - to follow (potentially) a broad range of urea concentration changes the urease- $\mathrm{NH}_{4}{ }^{+}$-ISE is recommended, especially working with the $\mathrm{pH}$ close to 5. Furthermore, for high sensitivity of the low concentration of urea determination, urease- $\mathrm{H}^{+}$-ISE is recommended, preferably working with a buffer-free solution.

\section{Acknowledgments}

This work was partially funded through the Foundation for Polish Science Ventures Programme and co-financed by the EU European Regional Development Fund (VENTURES/2012-9/5) (EJ). Financial support from the National Science Centre (NCN), Poland, project 2011/03/B/ST4/00747, in the years 2012-2015, is gratefully acknowledged (KM and AM).

\section{Author Contributions}

E.J. performed the experiments; A.M. and E.J. conceived and designed the experiments; A.M. and K.M. analyzed the data; A.M., K.M. and E.J. wrote the paper. 


\section{References}

1. Guilbault, G.; Nagy, E. Improved urea electrode. Anal. Chem. 1973, 45, 417-419.

2. Karyakin, A.A.; Bobrova, O.A.; Lukachora, L.V.; Karyakin, E.E. Potentiometric biosensors based on polyaniline semiconductor films. Sens. Actuators B: Chem. 1996, 33, 34-38.

3. Wan, K.; Chovelon, J.M.; Jaffrezic-Renault, N. Enzyme-octadecylamine Langmuir-Blodgett membranes for ENFET biosensors. Talanta 2000, 52, 663-670.

4. Davies, O.G.; Moody, G.J.; Thomes, J.D.R. Optimisation of poly(vinyl chloride) matrix membrane ion-selective electrodes for ammonium ions. Analyst 1988, 113, 497-500.

5. Ghavri, M.S.; Thomas, J.D.R. Evaluation of an ammonium ionophore for use in poly(vinyl chloride) membrane ion-selective electrodes: Solvent mediator effects. Analyst 1994, 119, 2323-2326.

6. Michalska, A. All-solid-state ion selective and all-solid-state reference electrodes. Electroanalysis 2012, 24, 1253-1265.

7. Crespo, G.A.; Macho, S.; Rius, F.X. Ion-selective electrodes using carbon nanotubes as ion-to-electron transducers. Anal. Chem. 2008, 80, 1316-1322.

8. Crespo, G.A.; Macho, S.; Bobacka, J.; Rius, F.X. Transduction mechanism of carbon nanotubes in solid-contact ion-selective electrodes. Anal. Chem. 2009, 81, 676-681.

9. Rius-Ruiz, F.X.; Crespo, G.A.; Bejarano-Nosas, D.; Blondeau, P.; Riu, J.; Rius, F.X. Potentiometric strip cell based on carbon nanotubes as transducer layer: Toward low-cost decentralized measurements. Anal. Chem. 2011, 83, 8810-8815.

10. Hernández, R.; Riu, J.; Rius, F.X. Determination of calcium ion in sap using carbon nanotube-based ion-selective electrodes. Analyst 2010, 135, 1979-1985.

11. Mousavi, Z.; Teter, A.; Lewenstam, A.; Maj-Zurawska, M.; Ivaska, A.; Bobacka, J. Comparison of multi-walled carbon nanotubes and poly(3-octylthiophene) as ion-to-electron transducers in all-solid-state potassium ion-selective electrodes. Electroanalysis 2011, 23, 1352-1358.

12. Novell, M.; Parrilla, M.; Crespo, G.A.; Rius, F.X.; Andrade, F.J. Paper-based ion-selective potentiometric sensors. Anal. Chem. 2012, 84, 4695-4702.

13. Jaworska, E.; Lewandowski, W.; Mieczkowski, J.; Maksymiuk, K.; Michalska, A. Simple and disposable potentiometric sensors based on graphene or multi-walled carbon nanotubes carbon plastic potentiometric sensors. Analyst 2013, 138, 2363-2371.

14. Jaworska, E.; Schmidt, M.; Scarpa, G.; Maksymiuk, K.; Michalska A. Spray-coated all-solid-state potentiometric sensors. Analyst 2014, 139, 6010-6015.

15. Meyerhoff, M.E. Polymer membrane electrode based potentiometric ammonia gas sensor. Anal. Chem. 1980, 52, 1532-1534.

16. Głąb, S.; Koncki, R.; Kopczewska, E.; Walcerz, I.; Hulanicki, A. Urea sensors based on PVC membrane pH electrode. Talanta 1994, 41, 1201-1205.

17. Koncki, R.; Leszczyński, P.; Hulanicki, A.; Głąb, S. Urea sensors based on glass pH electrodes with physically immobilized urease. Anal. Chim. Acta 1992, 257, 67-72.

18. Setitogullari, A.; Uslan, A.H. Preparation of a potentiometric immobilized urease electrode and urea determination in serum. Talanta 2002, 57, 1039-1044. 
19. Wałcerz, I.; Koncki, R.; Leszczyńska, E.; Salomonowicz, B.; Głąb, S. Urea biosensors based on PVC membrane ion-selective electrodes. Anal. Lett. 1996, 29, 1939-1953.

20. Koncki, R.; Mohr, G.J.; Wolfbeis, O.S. Enzyme biosensor for urea based on a novel pH bulk optode membrane. Biosens. Bioelectr. 1995, 10, 653-659.

21. Jaworska, E.; Kisiel, A.; Maksymiuk, K.; Michalska, A. Lowering the resistivity of polyacrylate ion-selective membranes by platinum nanoparticles addition. Anal. Chem. 2011, 83, 438-445.

22. Michalska, A.; Maksymiuk, K. All-plastic, disposable, low detection limit ion-selective electrodes. Anal. Chim. Acta 2004, 523, 97-105.

23. Kisiel, A.; Michalska, A.; Maksymiuk, K. Plastic reference electrodes and plastic potentiometric cells with dispersion cast poly(3,4-ethylenedioxythiophene) and poly(vinyl chloride) based membranes. Bioelectrochemistry 2007, 71, 75-80.

24. Cesareo, S.D.; Langton, S.R. Kinetic properties of Helicobacter pylori urease compared with jack bean urease. FEMS Micobiol. Lett. 1992, 78, 15-21.

(C) 2015 by the authors; licensee MDPI, Basel, Switzerland. This article is an open access article distributed under the terms and conditions of the Creative Commons Attribution license (http://creativecommons.org/licenses/by/4.0/). 